\title{
Application of Research-Oriented Teaching Mode in History Teaching in Colleges
}

\author{
Xianrong $\mathrm{Yu}$ \\ Ganzhou Teachers College, Ganzhou Jiangxi, China.
}

\begin{abstract}
Research oriented teaching mode is a new teaching direction of new curriculum reform, aiming at training comprehensive historical talents and promoting the development of historical career. The history teaching in Colleges and universities is badly in need of research-based teaching mode. Combined with relevant teaching practice, it gives students enough learning space and achieves good teaching results.
\end{abstract}

Keywords: University history teaching; research teaching mode; historical research method.

\section{研究型教学模式在高校历史教学中的应用}

\author{
余先荣 \\ 赣州师范高等专科学校, 江西赣州, 中国
}

摘 要: 研究型教学模式是新课改的新教学方向, 旨在培养综合性历史人才, 推动历史事业发 展。高校历史教学急需研究型教学模式, 结合相关教学实践, 给予学生充分的学习空间, 进 而取得良好的教学效果。

关键词: 高校历史教学; 研究型教学模式; 史学研究方法

\section{1. 引言}

历史学科旨在培养学生爱国情感并提升德育思想, 有助于其综合素质提高。高校历史教学虽 然内在逐渐进步, 但是一直以来都存在部分难题未能得到解决。例如历史教学过程中无法制 定具体的教学目标, 一旦拓展知识点, 就可能导致课时短缺。同时, 历史教学过于重视传授 历史知识, 仅仅将知识停留于教材内部, 忽略学生的自主学习能力以及实践能力的培养。此 外, 教师与学生的互动较少, 学术活动较为匮乏, 不仅难以结合专业学习, 而且容易导致学 生丧失学习主动性。以上问题不反映出传统高校历史教学的弊端。传统教学模式在教学内容 上强调传承性以及封闭性, 但是忽略创造性以及个性化发展, 教学手段更偏重于系统化, 而 忽略实践。因此, 本文将通过部分大学的历史教学方式来讲解研究型教学模式的必要性以及 效果。

所谓研究性教学模式, 是指在教师的细心教导下, 学生从教学内容中获取相关的研究方向, 通过历史学角度来探索其中奥秘, 主动查阅文献、整理并归纳相关问题, 自主解决问题。此 过程可以简化为: 发现问题、采集资料、构建知识体系以及展现自我。研究型教学模式中, 师生关系会更加紧密, 同时学生占据教学的主体地位。

\section{2. 高校历史教学中实施研究型教学模式的必要性}

\section{1. 培养复合型人才的现实需要}

高等教育的培养目标是打造综合型人才, 满足社会的需求。如今, 高校历史专业的学生会选 择考研或者考取教师资格证, 甚至部分学生选择其他行业。当然, 学生必须具备足够的历史 知识以及自主学习能力才能继续深造, 传统的教学模式不仅不利于学生开展科研训练, 而且 遇到过于灵活的题型便无从解答。其中, 类似于全球史观以及现代化理论等知识属于学习的 
重难点, 学生不知如何将其融合贯通。因此, 构建完善的知识体系是研究型教学模式的重要 目标。

2.2. 学生自身发展的现实需要

目前, 部分大学生缺乏足够的创新能力, 除天生条件的差异外, 最主要的因素是传统的教学 模式难以调动学生的学习积极性。根据调查得知, 目前, 部分高校历史专业的教学模式依然 以课堂教学为主, 学生依然采用做笔记、背书等方式来学习历史知识, 甚至部分学生的教材 从未翻开过。上述教学模式中, 学生仅仅是被动的知识接受者, 教师占据绝对的主体地位, 学生无法展现自己的想法, 也缺乏自主思考的空间, 不敢怀疑教师所讲述的知识, 进而降低 学习的欲望以及激情。如此, 学生也只是掌握所谓的历史知识, 撰写简单的毕业论文都变得 略为困难。根据调查发现, 大量毕业生仅仅将零零散散的论文拼凑成毕业论文, 甚至未曾仔 细阅读文献, 不了解权威的专家以及期刊, 日后进入社会将难以受到企业的赏识, 遇到困难 不知所措。

研究型教学模式下, 教师不只需要传授相应的历史知识, 更要通过沟通的方式引导学生主动 参与学习, 发现问题、解决问题, 迎难而上。这不仅是培养综合性人才的关键, 也是企业需 要的人才类型。

2.3. 历史学科发展的需要

历史学科属于高校的基础学科, 有助于提升爱国意识以及综合素养。这一特征决定历史学科 不仅是历史知识的传承, 更是培养基本的研究能力, 将其转化为专业素质过硬的应用性人才。 因此, 教师应当仔细把握历史学科的特征以及教学目标, 制定相应的教学计划, 创新教学模 式, 推动高校历史学科的发展。

\section{3. 高校历史课堂实施研究型教学模式的效果分析}

\section{1. 研究型教学模式实施过程介绍}

本文试图在世界当代史课堂中引入研究型教学模式, 这是由于此阶段的学生已经拥有足够的 历史基础, 同时具备足够的时间与教师共同完成文献采集以及其他准备工作。具体内容如下: 第一, 教师需要仔细讲述世界当代史的基本内容以及相关学术成果, 通过师生互动的方式来 确定主题。作者制定出以 “在世界当代史中你最感兴趣的内容是什么?” 为题的调查问卷, 在 课前分发给班级学生并向其确定部分主题, 允许班级学生根据自身爱好选择相应的小组。根 据调查结果，作者确定 “科学技术改变生活”、“文明冲突” 等主题。其次，教师应提供部 分优秀的历史书籍, 鼓励学生课后阅读文献, 其中涵盖电影、动画、短片等, 教师安排不同 的小组查找不同的资料类型以降低劳动量。学生查找完资料后可以实现在小组内部开展讨论, 然后将最终结论以小组形式提供给教师。然后, 教师将不同小组的成果呈现在课堂之上, 允 许每个小组选取相应的代表人制作课件并上台演讲, 阐述自己小组的研究内容, 演讲过程中 允许组内成员及时补充, 同时其他小组可以随时提问, 所有学生演讲完毕后, 教师应当公正 评判。最后, 研究型教学课程结束后, 教师应当抽取部分时间在网络中或者问卷中了解学生 的听课感受, 就学生的意见进行总结反思。此外, 学生也应认真思考研讨课的优势以及不足, 及时提供给教师以促进教学发展。

3. 2. 研究型教学模式实施的效果分析

为评估研究型教学模式的实施效果, 本文会在课后为每位学生发放调查问卷, 并及时回收。 调查结果如下:

首先, 绝大多数学生认为研究型教学模式具有成效, 表示认可。对于是否有必要增多提问时 间的问题, 绝大多数学生认为可以接受并应当在其他专业学科中推广。由此可见, 与传统的 教学模式相比, 学生偏爱互动性较强的研究型教学模式。

其次, 学生都认为研究型教学模式有效提高自己的学习兴趣, 同时提高自己的主体地位, 并 愿意主动参与研讨任务, 这一调查显示学生主体角色意识方面有所提升。同时, 大多数学生 在课后发现自己的研究能力以及自主学习能力有待提升, 而且对研讨主题具有全新的看法。 
此外, 大多数学生认为自己的学习思路在一定程度上有所扩展。学生在确定主题、采集文献、 互动交流以及上台演讲等环节均积极参与, 从过去的被动学习转化为主动学习, 同时在研究 过程中自主分析并解决部分历史问题。

最后, 学生认为自己的写作能力得到提高。大多数学生通过完成主题论文的任务了解到部分 历史论文的写作方法, 此效果得到学生的一致好评, 他们认为这种教学方式有助于其从文献 内抽取有用的信息。教师通过对学术界最新研究动态的介绍将学生引领到科学前沿, 为将来 从事开创性的研究工作打下基础。在研究型教学模式中, 学生通过查找资料进行专题研究, 这对于学生创新能力的培养和人生目标的定位大有裨益。

\section{4. 结束语}

综上所述, 提高学生在教学过程的主体地位, 要求其参与确定主题、搜集资料、互动讨论以 及上台演讲等环节, 得到学生的一致好评。学生从此课堂中展现自己的特色并获得教师的公 正评价, 有助于其认真反思自己的优势以及缺陷, 并逐渐提高历史研究能力。此外, 学生在 该课程学习中感受到历史工作的流程, 进而对未来工作有了大致的认识。最终, 研究型教学 模式锻炼和发展学生的分析能力、科学创新能力和团队协作能力, 有效加强高效的历史教学 质量, 推动历史教学发展。

\section{References}

[1]. Wang Laying. Several issues that should be paid attention to in the teaching of history in the Internet age. [J]. higher education journal, 2018 (5): 82-84.

[2]. Yu Xianrong. The teaching of history and the cultivation of students' Humanistic Quality in Colleges and universities. A comparative study of [J].'S cultural innovation, 2018 (4).

[3]. Yan Jing Ping. The evolution of Chinese modern history education in Colleges and universities and the connection of history education [J]. Journal of Chifeng University (Chinese philosophy and Social Sciences Edition), 2018 (2): 146-148.

[4]. Wu Qi. Problems and suggestions in the history of general education in Colleges and universities [J]. History teaching (second half), 2018 (1).

[5]. Li Yue Xin. Comment on the classroom teaching mode of "ancient Chinese history" in university history major, [J]. Journal of Mudanjiang Institute of education, 2018 (2).

[6]. Yang Xinyang. On the reform of teaching mode of Chinese ancient history in the information age, [J]. Chinese training, 2016 (22): 137-138. 